\title{
Paraurethral leomyoma: a manageable challenge
}

\section{Ritu Khatuja ${ }^{1}$, Menka Verma ${ }^{1 *}$, Nivedita Sarda ${ }^{1}$, Dolly Chawla ${ }^{1}$, Renu Gupta ${ }^{2}$, Pratima Khare ${ }^{2}$}

\begin{abstract}
${ }^{1}$ Department of Obstetrics and Gynecology, ${ }^{2}$ Department of Pathology, Baba Saheb Ambedkar Hospital and Medical
\end{abstract} College, New Delhi, India

Received: 21 March 2017

Accepted: 21 April 2017

*Correspondence:

Dr. Menka Verma,

E-mail: dr.menkaverma@gmail.com

Copyright: (C) the author(s), publisher and licensee Medip Academy. This is an open-access article distributed under the terms of the Creative Commons Attribution Non-Commercial License, which permits unrestricted non-commercial use, distribution, and reproduction in any medium, provided the original work is properly cited.

\section{ABSTRACT}

Leiomyoma is a most common benign tumour of uterus. But it is very rare in vagina urethral and paraurethral. There are approximately 330 case reports are available in literature and the paraurethral site is extremely uncommon. Here, we report a case of 38-year nulliparous woman presented with complain of mass coming out of vagina as well as dyspareunia. Provisional diagnosis of anterior vaginal cyst along with the differential diagnosis of paraurethral and anterior wall vaginal leiomyoma was made. Transvaginal removal of mass was done and diagnosis of paraurethral leiomyoma was confirmed by histopathology.

Keywords: Benign, Leiomyoma, Paraurethral

\section{INTRODUCTION}

Leiomyomas are one of the most common benign tumours of uterus but in rare cases it may be found in vagina. There are only 300-330 cases have been reported till date. ${ }^{1,2}$ These benign tumours have various clinical presentation such as swelling, something coming out of vagina, dyspurunia, dysuria and pain in lower abdomen. The most common age group is between 35-50 years and it may or may not be associated with leiomyoma elsewhere in the body. Here we report the case of a nulliparous woman with leiomyoma of vagina with complaints of mass coming out of vagina and dysparunia. Diagnosis was confirmed by histopathological report. ${ }^{3,4}$

Leiomyomas are one of the most common benign tumours of uterus but in rare cases it may be found in urethral, paraurethral, or anterior vaginal wall. Approximately so far 40 cases of urethral tumour and 250 vaginal tumour are reported in literature and out of urethral tumour 6 has been reported as paraurethral tumour. Paraurethral leomyoma is a rare, benign hormone dependent neoplasm of mesenchymal origin affecting women of reproductive age group. The clinical presentation varies but it usually asymptomatic, or present with foreign body sensation or something coming out of vagina, urinary symptom not so commonly seen. To distinguish among them can be difficult due to their close anatomic proximity. ${ }^{1,2}$

Here we report the case of a nulliparous woman with paraurethral leiomyoma of vagina with complaints of mass coming out of vagina and dysparunia. Diagnosis was confirmed by histopathological report.

\section{CASE REPORT}

We have presented with a 38 years nulliparous women complaining of something coming out of vagina on staining since 2 years which was gradually increased in size over a period of time. She also complaint of itching over the vulva and dysparunia for two years. On local 
examination women had leukoplakia over the vulva and a $4 \times 5 \mathrm{~cm}$ mass found on anterior vaginal wall. On per speculum examination mass of $4 \times 5 \mathrm{~cm}$ seen just below the urethra on anterior vaginal wall and cervix is normal nulliparous looking. Per vaginal examination reveal mass was non-tender, regular, firm in consistency with restricted mobility. No exudate could have obtained with massage. Uterus and adenexa were normal. Per rectal examination was unremarkable.

Ultasonography suggestive of a midline well-defined $4.7 \times 4.4 \mathrm{~cm}$ hetrogenous space occupying lesion in vagina likely to be prolapsed fibroid. MRI could not be performed due to unaffordability of patient. Clinical impression of vaginal leiomyoma with leukoplekia was made. Patient was referred to surgeryl for urosurgical opinion in view of suspension of urethral involvment and underwent micturating cystourethrogram (MCU) which was normal. Patient was planned for vulva biopsy and excision of mass. All preoperative investigation patient was done for surgery. After spinal anesthesia, foley's catheterization done. Mass was excised through anterior vaginal wall, circular incision on vaginal mucosa given, capsule of fibroid was identified and the fibroid was encapsulated by blunt and sharp dissection. Care was taken to remove the base completely to avoid the chance of recurrence and taken care to avoid injury to urethra during excision. Urethrocystoscopy was performed and no external communication with urethra, bladder and vagina was noted. Vulva biopsy was taken and sent for histopathological examination (Figure 1).

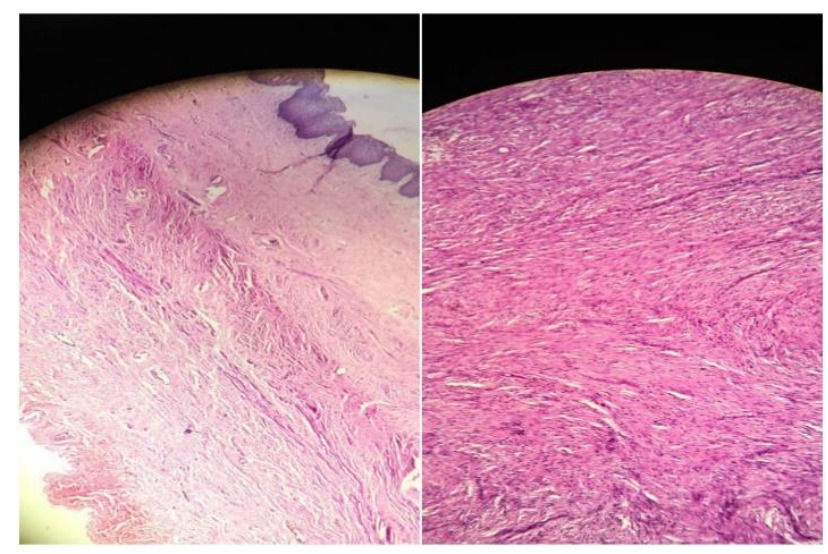

Figure 1: Histopathological slide reveals spindle smooth muscle cells with atypical features without mitotic activity suggestive of paraurethral leiomyoma.

On gross examine $4 \times 5$ solid mass with whorl appearance seen on cut section (Figure 2).

Postoperative period was uneventful and the woman was discharged on fifth post-operative day. Histopathological report revealed spindle smooth muscle cells with atypical features without evidence of mitotic activity suggestive of paraurethral leiomyoma and vulva biopsy report came to be of chronic inflammation and edema. The patent was completely relieved from the symptoms.

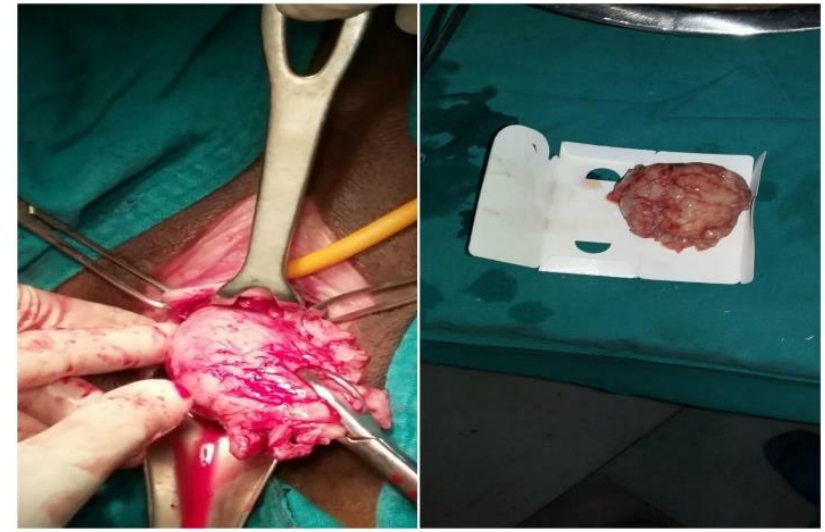

Figure 2: On gross examination $4 \times 5 \mathrm{cms}$ mass with whorl like appearance on cut section.

\section{DISCUSSION}

Paraurethral leiomyoma are benign genitourinary tumour that are exceedingly rare. Are usually small and asymptomatic but occasionally grow large in size, lead to urethral obstruction or dysparunia. ${ }^{5}$

The distinction between urethral, paraurethral and vaginal are difficulty due to their close proximity. Clinical and histological presentation is same. Differentiation is made on basis of its location the female urethra and anterior vaginal wall are thin but durable structure made of multiple layers. ${ }^{6}$

Female urethra has mucosal lining followed by highly vascular sub mucosa made of connective tissue comprises of elastic and smooth muscle fibres, provides excellent seal at the urethral closure. External layer consists of circumferential layers of smooth muscle contained in a fibrous connective tissue layer. A skeletal muscle (rhabdosphincter) surround smooth muscle in a horseshoe fashion and most prominent at mid urethra. The anterior vaginal wall consist of thick rugated epithelium below this submucosa comprises of collagen and elastic fibres followed by fibromuscular band with smooth muscle bundle oriented in an inner longitudinal and an outer circular fashion. The muscle layer is contained within a thick fibrous capsule that is juxtaposed to the periurethral fascia location wise leiomyoma is most common on posterior urethral wall in urethra and anterior vaginal wall in vagina. Paraurethral arises between juxtaposed tissue or in vesicovaginal septum. ${ }^{6}$

Paraurethral leiomyoma usually present in fourth or fifth decade of life. Fifty percent are asymptomatic usually present as something coming out of vagina, dysparenia or rarely urinary symptoms. It was also seen in our case as patient was presented with something coming out of vagina, dysparunia and itching over the vulva. ${ }^{6}$ Preoperative USG and MRI is usually help in the diagnosis as well as to estimate, characteristic and involvement of mass. ${ }^{7}$ Histopathology is giving the confirmation of diagnosis. Surgical excision of mass by 
vaginal route with urethral catherization is the treatment of choice. It is suggested that it should be remove in toto to prevent recurrence. ${ }^{8}$ Patient needed to follow up for chances of recurrence. We have made the provisional diagnosis and assess the extent of tumor on the basis of clinical and ultrasound finding as we are from low resources countries and MRI is not usually performed. We have done the MCU preoperatively and urethrocystoscopy postoperatively as paraurethral leiomyoma lead to indent the bladder which may cause bladder injury which was also reported by Smitha V et al. ${ }^{9}$ In our case we also found there was chronic inflammation of vulva which may be due to paraurethral leiomyoma.

Radiographic imaging studies including intravenous pyelography, voiding cystourethrography, urethrography, vagina transonography, pelvic MRI may be helpful in defining its connection with urinary tract. The differential diagnosis for paraurethral mass includes various condition arising from genitourinary tract it can be vaginal wall cyst, urethral prolapse, caruncle, urethral diverticulum, urethral leomyoma, cervical fibroid, polyp and cystocoele. ${ }^{9,10}$

\section{CONCLUSION}

It is very important for everyone to be familiar with broad differential masses of paraurethral region in order to streamline the patient management and facilitate favourable patient outcome because what the mind does not know, the eyes cannot see.

\section{ACKNOWLEDGEMENTS}

The authors would like to acknowledge the patient for consenting to reveal the case details and photographs for publication.

Funding: No funding sources Conflict of interest: None declared

\section{Ethical approval: Not required}

\section{REFERENCES}

1. Chakrabarti I, De A, Pati S. Vaginal leiomyoma. J Midlife Health. 2011;2(1):42-3.

2. Young SB, Rose PG, Reuter KL. Vaginal fibromyomata: two cases with preoperative assessment, resection and reconstruction. Obstet Gynecol. 1991;78:972-4.

3. Bennett HG, Ehrlich MM. Myoma and vagina. Amm J Obstet Gynecol. 1941;42:314-20.

4. Nel CP, Tiltman AJ. Liomyoma of vagina. S Afr Med J. 1978;54:816-7.

5. Patou $\mathrm{T}$, Lalana $\mathrm{S}$, Voranuch $\mathrm{T}$, Nakarin $\mathrm{S}$. Paraurethral leiomyoma: a case report. J Med Assoc Thai. 2006;89(4):545-9.

6. Jeffrey H. Martin, Edward R. Gerrard, Paraurethral Leiomyoma: Does Making the Distinction Make a Difference?. Infect Urol. 2001;14(2).

7. Sherer DM, Cheung W, Gorelick C. Sonographic and magnetic resonance imaging findings of an isolated vaginal leiomyoma. J Ultrasound Med. 2007;26(10):1453-6.

8. Gowri R, Soundavaraghvan S, Oumachigvi A, Sistin $\mathrm{SC}$, Iyenger KR. Leiomyoma of the vagina: An unusual presentation. J ObstGyn Res. 2003;29:395-8.

9. Nidhanee SV, Maiti S, Shareef D, Holland N. An unusual presentation of a vaginal leiomyoma in a postmenopausal hysterectomised woman: a case report. Cases J. 2009;2:6461.

10. Costantini E, Cochetti G, Porena M. Vaginal paraurethral myxoid leiomyoma: case report and review of the literature. Int Urogynecol J Pelvic Floor Dysfunct. 2008;19(8):1183-5.

Cite this article as: Khatuja R, Verma M, Sarda N, Chawla D, Gupta R, Khare P. Paraurethral leomyoma: a manageable challenge. Int J Reprod Contracept Obstet Gynecol 2017;6:2641-3. 